\title{
AVALIAÇÃO DOS NÍVEIS DE PRESSÃO SONORA AOS QUAIS MÚSICOS DE UMA BANDA ESTÃO EXPOSTOS
}

\section{EVALUATION OF THE SOUND PRESSURE LEVELS ON BAND MUSICIANS}

\author{
Márcio Henrique Mendes \\ Universidade Tecnológica Federal do Paraná - UTFPR, Campus Curitiba
}

Av. Sete de Setembro, no 3165 - Curitiba - PR - 80230-901

Tel.: (41) 33104607 - E-mail: marciohmendes@ @otmail.com

\author{
Rodrigo Eduardo Catai \\ Professor Adjunto, Dr. \\ Departamento Acadêmico de Construção Civil \\ Universidade Tecnológica Federal do Paraná - UTFPR, Campus Curitiba \\ Av. Sete de Setembro, no 3165 - Curitiba - PR- 80230-901 \\ Tel.: (41) 33104607 -E-mail: catai@utfpr.edu.br \\ Mauro Edson Alberti \\ Professor Adjunto, Msc. \\ Departamento Acadêmico de Construção Civil \\ Universidade Tecnológica Federal do Paraná - UTFPR, Campus Curitiba \\ Av. Sete de Setembro, no 3165 - Curitiba - PR- 80230-901 \\ Tel.: (41) 33104607 - E-mail: alberti@utfpr.edu.br
}




\title{
RESUMO
}

Este artigo apresenta os resultados e as discussões sobre as medidas dos níveis de pressão sonora aos quais músicos estão expostos em sua jornada de trabalho. O objeto de estudo é uma banda, estilo rock-pop, composta por cinco integrantes. O método utilizado para as medições dos níveis de ruído consistiu na avaliação dos níveis de pressão sonora por meio de um medidor de nível de pressão sonora. As medidas foram feitas em dias diferentes e em dois locais: no ambiente usado para ensaios e em uma casa de shows destinada a apresentações. Foi constatado que os níveis a que os músicos analisados foram expostos estão acima dos limites das normas vigentes. Os resultados mostraram que é possível minimizar os valores de pressão sonora por meio de medidas simples, como o uso de equipamento de proteção individual e correções inerentes à acústica ambiental.

Palavras-chave: ruído, músicos, nível de pressão sonora.

\begin{abstract}
This paper presents the results and discussions about the measurements of the sound pressure levels which musicians are exposed in working with music presentations. The object of the research is a five integrants rock-pop band. The applied method for the noise levels measurements consisted of the sound pressure levels evaluation with a sound level meter. The measurements were made in different days and in two different conditions: indoor room used for rehearsing and the show house designated for presentations. It was founded that the levels which musicians were exposed are higher than the limits of standard norms. The results showed that it is possible to perform some actions to reduce the sound pressure levels, as the use of individual protection equipment and the ambient acoustic improvement.
\end{abstract}

Key-words: noise, musicians, sound pressure level.

\section{INTRODUÇÃO}

A exposição a níveis de pressão sonora elevados por longos períodos de tempo pode não apenas gerar perturbações funcionais no organismo, como também causar problemas que vão desde o incômodo até sérias lesões auditivas, as quais muitas vezes são irreversíveis.

O músico é um profissional que exerce sua atividade, na maioria das vezes, sob intensos níveis sonoros tanto em suas performances (shows) quanto em suas práticas de treinamento e estudo, ao longo de várias horas de dedicação e ensaios. A música em 


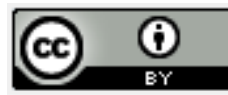

orquestras sinfônicas e/ou banda de estilos variados frequientemente ultrapassa os padrões de intensidade toleráveis, atingindo níveis de pressão sonora elevados.

A preocupação com os efeitos dos níveis intensos de sonoridade na saúde auditiva dos músicos tem aumentado nos últimos anos, com o advento da evolução dos sistemas de som e desenvolvimento dos equipamentos eletrônicos de áudio. De acordo com vários autores, o apogeu de transformação da música foi aproximadamente em 1960, quando do aparecimento do estilo "rock and roll", que alavancou o surgimento da música maciçamente amplificada. Nesta época, o som dos Beatles, por exemplo, apresentava uma potência na ordem de 100 watts. Por volta de 1990, este valor já se encontrava na ordem de 500 mil watts (ANDRADE et al., 2002; BARATA, 2002; FERNANDES e MORATA, 2002; PAIXÃO et al., 2004).

Sabe-se que o recurso mais importante na vida profissional de um músico é a sua audição e, no entanto, essa muitas vezes se encontra sob risco. Desta forma, muitos trabalhos encontrados na literatura especializada têm seu principal foco nas medições de níveis sonoros e suas conseqüências. A importância da audição para os músicos, em oposição aos riscos decorrentes do som intenso, levou os autores a demonstrarem a necessidade de informação e a possibilidade de minimizar os efeitos nocivos devido à exposição prolongada a níveis intensos de sonoridade.

Desta forma, este artigo tem como objetivos: avaliar preliminarmente os níveis de pressão sonora, aos quais os cinco músicos de uma banda, de estilo rock-pop da cidade de Curitiba (PR), estão expostos durante a rotina de ensaios em um ambiente isolado acusticamente; analisar o comportamento do integrante da banda que está sujeito aos maiores níveis de pressão sonora durante os ensaios, em um evento realizado pela banda em uma casa de shows; e, sugerir soluções para que os integrantes da banda possam não sofrer com as conseqüências da exposição aos elevados níveis sonoros aos quais estão expostos.

\section{REVISÃO BIBLIOGRÁFICA}

\subsection{RUÍDO}

O ruído pode ser conceituado de diferentes maneiras, dependendo da análise e atividade em questão. De uma maneira geral, pode-se obter uma conceituação física e outra subjetiva. Fisicamente o ruído é um fenômeno composto de várias ondas sonoras, compostas 


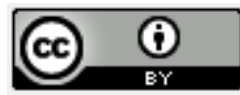

de diversas vibrações que não apresentam relações entre si e que se apresentam de forma aperiódica acusticamente. De forma subjetiva, segundo Iida (2005), o ruído pode ser conceituado como um som indesejável, porém, dependendo da atividade em execução e da ocasião em questão.

Já Almeida et al. (2000) afirmam que o ruído é um fenômeno acústico constituído de diversas ondas sonoras relacionadas com a amplitude e fases dispostas aleatoriamente, que produzem uma sensação auditiva desagradável.

De acordo com Fernandes (2002), o ruído caracteriza-se por ser um som complexo, resultado da superposição desarmônica de sons originados de várias fontes.

Segundo Ruiz et al. (2000), o ruído é uma mescla de diferentes sons, no qual sua freqüência não compõe uma ordem lógica.

A NR-15 - Norma Regulamentadora de Segurança e Medicina do Trabalho do Ministério do Trabalho fixa os limites de tolerância para exposição ao ruído e classifica-os em três tipos: contínuo, intermitente e de impacto. A norma não diferencia o ruído contínuo do intermitente, apontando apenas que seriam os ruídos que não são de impacto. Este último conceitua-se como sendo um pico de energia sonora com duração menor que 1 segundo, com intervalos maiores que 1 segundo (BRASIL, 2006a).

De acordo com Gerges (2000), o ruído é um tipo sonoro desagradável e indesejado. O autor ainda explicita que a potencialidade de perturbações auditivas não se deve apenas ao nível de som, mas também ao tempo de exposição.

Por fim, Bistafa (2006) define ruído como um som sem harmonia, e na maioria das vezes de sentido negativo. $\mathrm{O}$ autor ainda infere que tal definição depende do contexto e expõe que sons com qualificação de ruído podem passar informações úteis, como por exemplo, alerta sonoro indicando velocidade de direção (em automóveis) ou som indicando que o café de uma cafeteira está pronto.

É importante ressaltar que o nível sonoro equivalente $\mathrm{L}_{\mathrm{eq}}$ pode ser definido como um nível de ruído contínuo que possui a mesma energia acústica que os níveis oscilantes de origem, durante certo período de tempo. O L eq é definido pela Equação 1 (BISTAFA, 2006).

$$
L e q=10 \log \frac{1}{T} \int_{0}^{T} \frac{P^{2}(t)}{P_{0}^{2}} d t
$$

onde:

“ $P$ ” refere-se à pressão sonora instantânea, em N/m²; 


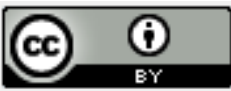

“ $P_{0}$ ” é a pressão sonora de referência $\left(2 \times 10^{-5} \mathrm{~N} / \mathrm{m}^{2}\right)$;

" $T$ ” é o tempo de integração.

\subsection{LIMITES DE CONFORTO ACÚSTICO}

As normas responsáveis pelos limites de tolerância adotados para se avaliar o nível de ruído no ambiente e dizer se o mesmo é insalubre ou não, variam de acordo com o ambiente analisado. A NBR 10.152 é a norma de níveis de som para o conforto acústico em ambiente construído.

Com relação ao conforto acústico no trabalho, na Norma Regulamentadora do Ministério do Trabalho, NR 17 - Ergonomia, encontram-se os parâmetros que promovem a adaptação das condições de trabalho às características psicofisiológicas dos trabalhadores de modo a oferecer conforto acústico, desempenho e segurança. Segundo esta mesma Norma, em locais onde se fizer necessário atenção constante ou ainda onde se exija solicitação intelectual recomenda-se que para conforto se tenha níveis de ruído de acordo com o estabelecido na NBR 10.152, norma brasileira registrada no INMETRO. No caso do valor limite de ruído não estar contemplado na NBR supracitada, deve-se ter como ruído máximo para conforto acústico o valor de até $65 \mathrm{~dB}(\mathrm{~A})$ ou $60 \mathrm{~dB}(\mathrm{C})$ (BRASIL, 2006b).

\subsection{CONSEQÜÊNCIAS DA EXPOSIÇÃO AO RUÍDO}

Currie e Kennedy (2002) afirmam que os músicos não se atentam que danos irreversíveis podem ser causados em suas audições, pois a lesão auditiva é invisível e cumulativa. Muitos estudos relacionados à exposição de músicos a altos níveis de pressão sonora e efeitos dessa exposição encontram-se na literatura, especialmente nas áreas de Fonoaudiologia, Engenharia de Segurança e Ergonomia.

Toppila et al. (2004) afirmam que a diferença entre profissionais industriais e músicos está relacionada ao número de fatores de risco. Portanto, sugere-se que a baixa perda auditiva observada em músicos não está associada ao fato de a música em elevados níveis apresentar menor perigo, e sim por apresentar menores fatores de risco. A forma básica de preservação da audição industrial é o controle do ruído na fonte, mas isso não é aplicável a músicos. Alguns músicos são expostos a níveis que, eventualmente, excedem não somente o limiar de desconforto, como o padrão de exposição ocupacional. A dificuldade de se estabelecer os 


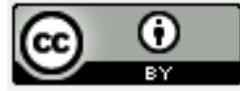

riscos para danos auditivos é dada ao fato de que os níveis sonoros são oscilantes e a exposição a níveis de sons intensos é intermitente.

Segundo a Associação dos Moradores do Distrito de Évora - AMDE (2003), o ruído atua através do ouvido sobre os sistemas nervoso central e autônomo. Quando o estímulo ultrapassa certos limites, produz-se surdez e efeitos patológicos em ambos os sistemas, tanto instantâneos como ao longo do tempo. Em níveis muito menores, o ruído produz incômodo e dificulta ou impede a atenção, a comunicação, a concentração, o descanso e o sono. A combinação destes efeitos pode ocasionar estados crônicos de nervosismo e stress, que possivelmente podem conduzir a problemas psicofísicos, doenças cardiovasculares e alterações do sistema de imunidade.

A diminuição do rendimento escolar e profissional, os acidentes de trabalho e de tráfego, algumas condutas anti-sociais e a tendência para o abandono das cidades, com o aumento da poluição sonora, são algumas das consequiências (AMDE, 2003).

\subsection{MEDIDAS DE CONTROLE DO RUÍDO}

Para a diminuição ou prevenção de emissão de sons indesejáveis podem ser tomadas várias medidas de controle que visam minimizar a intensidade sonora proveniente das atividades operacionais. Como forma de medidas preventivas de ruído industrial, Iida (2005) sugere algumas medidas:

- Atuação na fonte: fazer uma análise dos recursos utilizados no processo produtivo avaliando o impacto causado por máquinas e partes constituintes das mesmas e readequando ou substituindo por peças mais silenciosas.

- Isolamento da fonte: realizar o enclausuramento de máquinas dentro de cabines acústicas ou criar obstáculos de propagação do som, a fim de promover uma barreira total ou parcial da emissão de ruídos.

- Reduzir a reverberação: optar por materiais menos reflexivos na concepção estrutural do ambiente e das superfícies que o som encontra em sua trajetória. Uma medida que se pode tomar é o uso de materiais absorventes em pisos e paredes.

- Remoção do trabalhador: readequação do layout da fábrica, removendo o trabalhador das proximidades de alguma máquina ruidosa. Também se propõe que tendo possibilidade, deve-se realizar a colocação de máquinas emissoras de altos níveis de ruído em locais afastados do ambiente de trabalho dos trabalhadores. 


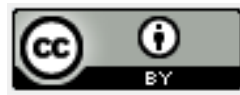

- Adoção de controles administrativos: a promoção de programas de conscientização dos trabalhadores sobre os efeitos de exposição ao ruído e treinamento de como trabalhar com salubridade ou uso de protetores individuais. Rodízio entre os membros da equipe de trabalho também pode refletir em medidas preventivas, uma vez que o trabalhador não fica exposto por tempos prolongados.

- Proteção do trabalhador: o uso de protetores individuais mostra-se como uma forma de proteção dos trabalhadores quando todas as medidas supracitadas apresentam-se ineficientes ou não economicamente viáveis.

\subsection{DOSE DE RUÍDO}

A dose de ruído (D) é a grandeza correspondente à soma da razão das parcelas de tempo de exposição atuais com os tempos de intervalos permitidos, conforme a Equação 2, e é uma ferramenta que acusa a porcentagem de exposição ao nível de ruído a que o indivíduo está submetido. Desta forma, o limite de tolerância de dose diária é 100\%.

Neste caso, o critério de dose de ruído foi obtido de maneira aproximada através da média aritmética dos valores de níveis sonoros equivalentes $\left(\mathrm{L}_{\mathrm{eq}}\right)$ para os três dias de análise com os valores de tempo permitidos pela NR-15 (BRASIL, 2006a).

$$
D=\frac{C_{1}}{T_{1}}+\frac{C_{2}}{T_{2}}+\ldots+\frac{C_{n}}{T_{n}}
$$

onde:

“ $C_{1}, C_{2} \ldots C_{n}$ ” correspondem aos segmentos atuais de tempo de exposição em níveis sonoros diferentes;

“ $T_{1}, T_{2} \ldots T_{n}$ ” são os tempos de intervalos permitidos.

\subsection{EXEMPLOS DE ESTUDOS EFETUADOS SOBRE O NÍVEL DE RUÍDO}

Andrade et al. (2002) realizaram um estudo com músicos de frevo e maracatu de blocos carnavalescos da cidade de Olinda-PE, a fim de medir os níveis de pressão sonora aos quais os mesmos estiveram expostos. Também fez parte da análise o levantamento dos níveis de audição do grupo, os hábitos auditivos e problemas relatados pelos participantes. Como resultado, mostrou-se que os hábitos mais apontados foram a freqüência em casas noturnas e 


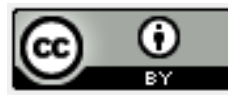

uso de walkman. As principais queixas apresentadas pelos músicos foram zumbido e tontura. Através de exames audiométricos, constatou-se que 42,10\% do grupo de frevo e $16,13 \%$ do grupo de maracatu tiveram resultados aparentes de PAIR (Perda de Audição Induzida por Ruído). Como conclusão, foi proposto a implantação de um programa de conservação auditiva.

Paixão et al. (2004) desenvolveram uma pesquisa com três grupos distintos de músicos de localidades diferentes e distantes. O primeiro composto por alunos concluintes do curso de música, o segundo por 33 (trinta e três) pianistas da Universidade do Estado de Santa Catarina - UDESC e o terceiro formado por músicos da Orquestra Sinfônica de Santa Maria - RS. O estudo consistiu na aplicação de um questionário referente aos conhecimentos de danos à saúde oriunda de níveis sonoros elevados. Dos resultados, constatou-se que $88 \%$ dos entrevistados do grupo da orquestra acreditavam que a exposição a altos níveis de pressão sonora poderia causar prejuízos à saúde e do grupo dos formandos, $93 \%$ tinham conhecimento desta afirmativa. Quando questionados se conheciam a legislação brasileira, e em especial a NR-15, 82,3\% do grupo da orquestra e 71,4\% dos graduandos não conheciam a existência da mesma. Destaca-se que nesta pesquisa, o zumbido foi apontado como principal queixa dentre os grupos, perfazendo um total de $15,2 \%$ dos pianistas e $23,5 \%$ no grupo da orquestra. Diante destes dados, os autores concluíram que são necessárias maiores informações aos alunos e profissionais da área sobre os riscos inerentes à atividade profissional.

Em 2004, Fernandes et al. (2004) desenvolveram uma pesquisa objetivando avaliar os níveis de intensidade sonora aos quais músicos de orquestras (ou bandas), da cidade de Bauru, ficavam expostos, bem como o tempo desta exposição. Os valores obtidos na medição foram comparados com os limites dispostos na norma NBR 10.152 e Portaria 3.124/78 do Ministério do Trabalho. Foram apontados níveis de som com média de 90 dB(A) com oscilações que chegaram a $110 \mathrm{~dB}(\mathrm{~A})$. Através da análise dos resultados, os autores puderam concluir que se tratava de um ambiente propício para o aparecimento de perdas auditivas.

\section{MATERIAIS E MÉTODOS}

Para a realização das medições de níveis sonoros, utilizou-se um medidor de nível de pressão sonora da marca Instrutherm, modelo DEC-5010, calibrado com um calibrador modelo CAL-3000, do mesmo fabricante, ambos com certificados de calibração. O medidor 


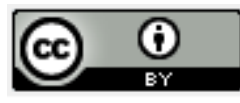

de nível de pressão sonora foi ajustado com curva de ponderação "A" e resposta lenta (slow), conforme recomenda a NBR 10.151.

Os níveis de pressão sonora foram medidos inicialmente durante 3 (três) dias distintos no local destinado às práticas de treinamento (ensaio) da banda. Após estas medições preliminares, identificou-se o "caso crítico", ou seja, o indivíduo que ficava exposto ao maior nível de pressão sonora durante os ensaios, para o avaliar novamente nas condições reais de uma casa de shows na cidade de Curitiba - PR. A Tabela 1 traz a caracterização de cada um dos cinco integrantes da banda musical do gênero rock-pop analisados.

Tabela 1 - Atividade por membro da banda musical

\begin{tabular}{c|c|c|c}
\hline Membro & Atividade/Instrumento & Idade (em anos) & $\begin{array}{c}\text { Tempo de atividade } \\
\text { musical (em anos) }\end{array}$ \\
\hline 1 & Vocais & 24 & 14 \\
\hline 2 & Guitarra & 26 & 17 \\
\hline 3 & Contrabaixo/Vocais & 30 & 18 \\
\hline 4 & Bateria & 32 & 18 \\
\hline 5 & Guitarra/Teclado/Vocais & 22 & 13 \\
\hline
\end{tabular}

\subsection{METODOLOGIA PARA AS MEDIÇÕES NO LOCAL DE ENSAIOS}

As medições no local de ensaios da banda, que possuía características acústicas peculiares, pois era destinado especialmente à gravação de áudio profissional, foram realizadas no período da segunda quinzena do mês de novembro do ano de 2006. A Figura 1 apresenta imagens do ambiente onde se transcorreram as medições.
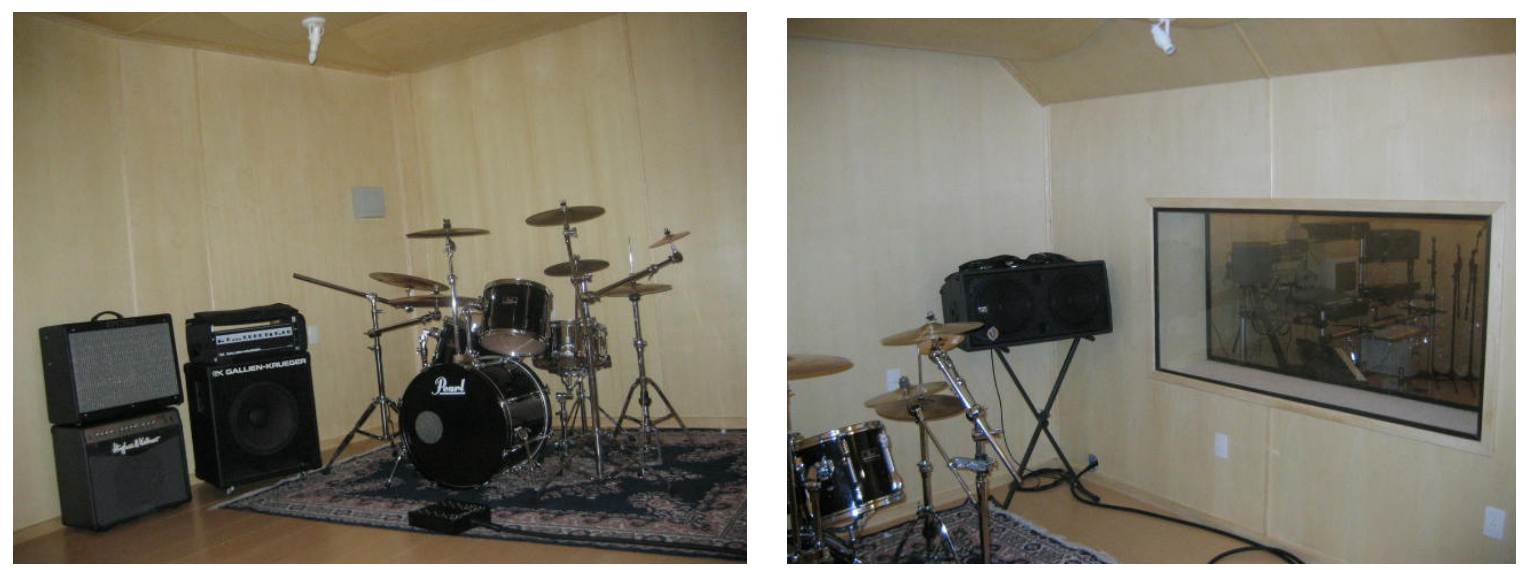

Figura 1 - Vista geral da sala de treinamento 
Destaca-se que a medição dos níveis sonoros foi feita ao lado dos cinco integrantes da banda dispostos no estúdio conforme a Figura 2. Ressalta-se que o layout foi o mesmo para todos os dias da análise, portanto, os indivíduos analisados permaneceram sempre nas mesmas posições.

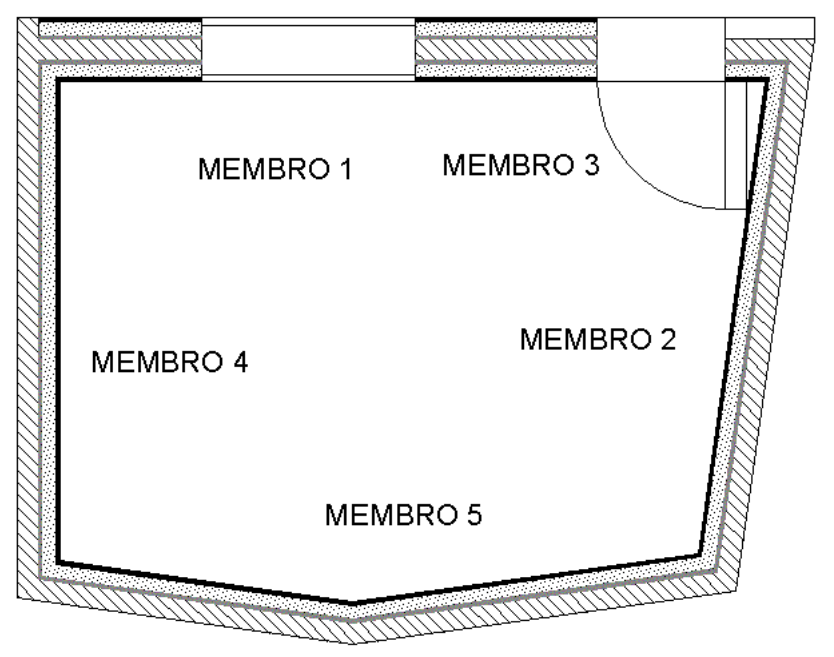

Figura 2 - Layout de posição dos músicos dentro da sala

Destaca-se que o nível sonoro foi obtido após o acompanhamento de cada membro da banda durante 6 minutos (360 segundos), registrando-se o valor de nível de pressão sonora NPS médio a cada período de 10 segundos, resultando numa amostra de 36 valores de NPS para cada componente da banda por dia de avaliação. Os valores obtidos na coleta de dados são apresentados no item 4.

Para uma caracterização em igualdade de condições dos diferentes membros da banda, as músicas executadas no período de medição foram de características similares, para, desta forma, ser possível realizar a comparação de resultados encontrados em cada uma das pessoas.

\subsection{METODOLOGIA PARA A MEDIÇÃO DO CASO MAIS CRÍTICO EM UMA CASA DE SHOWS}

A Figura 2 apresenta o layout de palco utilizado pela banda no show. Os pontos numerados correspondem ao posicionamento de cada elemento da banda. Para a realização da coleta de dados na casa de shows, procedeu-se da seguinte maneira: efetuou-se a medição ao lado do integrante que se apresentou como caso mais crítico durante o período de dez (10) 
minutos, fazendo o acompanhamento da variação de NPS emitido pelo grupo. Nessa mesma análise observou-se ainda o maior valor de NPS observado no período.

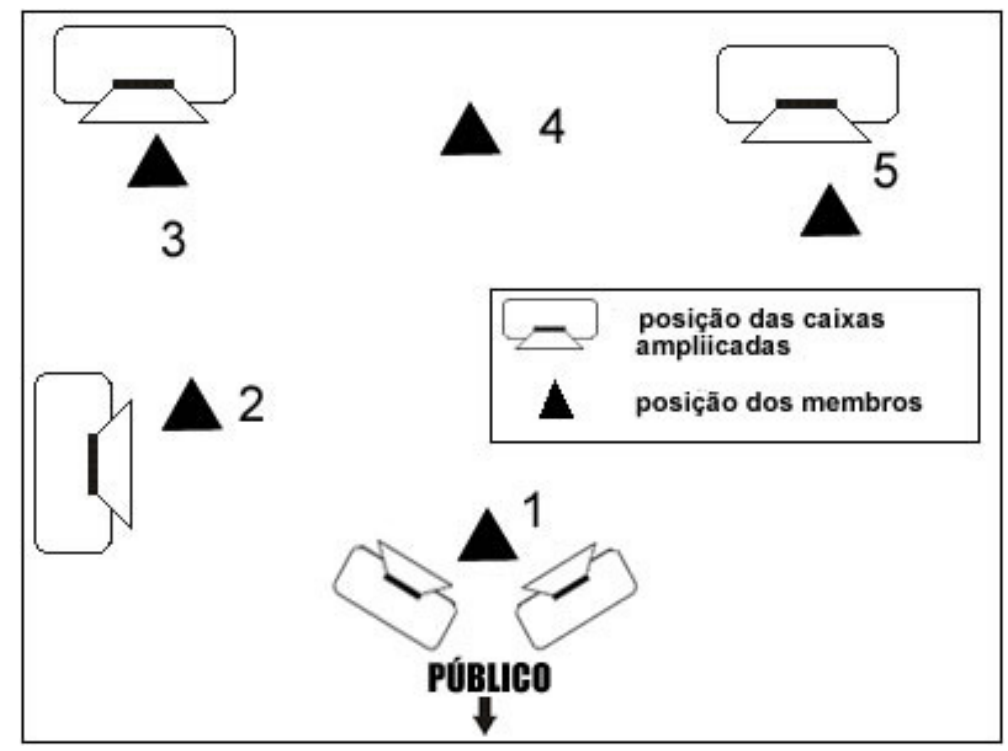

Figura 3 - Layout de palco utilizado pela banda

\section{RESULTADOS E DISCUSSÕES}

\subsection{RESULTADOS DAS MEDIÇÕES NO LOCAL DAS PRÁTICAS DE TREINAMENTO}

A Figura 4 expressa graficamente a variação do NPS para cada membro da banda na sala de treinamento durante 6 minutos. Destaca-se que cada ponto do gráfico refere-se à média dos valores obtidos nos três (3) dias de avaliação. A identificação de cada componente da banda está exposta na Tabela 1. Observa-se que durante os ensaios do grupo as músicas apresentaram estilos equivalentes. 


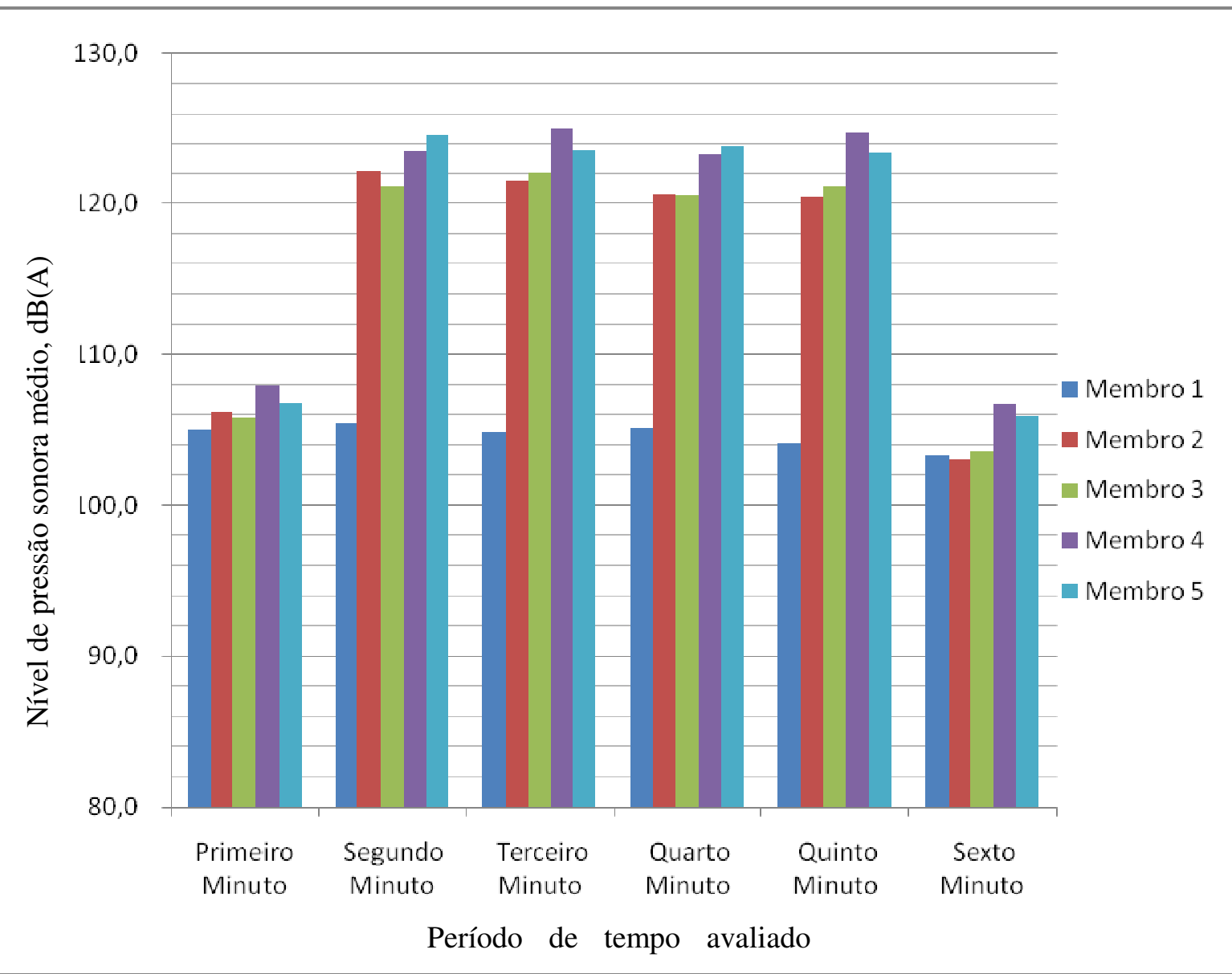

Figura 4 - Variação do NPS em função do intervalo de tempo medido para os cinco (5) integrantes da banda

Analisando-se a Figura 4 observa-se que os membros da banda que ficaram expostos aos maiores níveis de pressão sonora durante os seis intervalos de tempo medidos foram os membros 4 e 5 . Contudo pode-se notar que há uma leve predominância de maiores níveis de ruído no membro 4 (baterista), visto que este em quatro dos seis intervalos de tempo mensurados apresentou níveis de ruído acima dos apresentados pelo membro 5 (guitarrista/tecladista/vocalista). Esta leve predominância dos maiores níveis de ruído no baterista pode ser explicada pela dinâmica das músicas, que ora apresentavam elementos de guitarras distorcidas e/ou um ataque mais firme em algumas das peças que compõe a bateria.

Nota-se ainda na Figura 4 que os níveis de pressão sonora tendem a ser menores no primeiro e no sexto minuto, para todos os integrantes da banda, o que reflete o estilo não só desta banda, mais da grande maioria, que começa e termina as músicas com uma toada mais leve. 
A Tabela 2 apresenta os níveis sonoros equivalentes para cada um dos integrantes da banda durante o período de medição.

Tabela 2 - Níveis médios de ruído durante os 3 dias de ensaios para os 5 integrantes da banda

\begin{tabular}{c|c|c|c}
\hline Dia & $\mathbf{1}$ & $\mathbf{2}$ & $\mathbf{3}$ \\
\hline Membro & \multicolumn{3}{|c}{ Nível médio de ruído, } \\
& \multicolumn{3}{|c}{ dB(A) } \\
\hline 1 & 107,0 & 107,7 & 107,1 \\
\hline 2 & 107,0 & 107,5 & 107,8 \\
\hline 3 & 107,8 & 107,5 & 106,3 \\
\hline 4 & 110,4 & 108,8 & 109,1 \\
\hline 5 & 107,5 & 107,2 & 107,0 \\
\hline
\end{tabular}

Analisando-se a Tabela 2, verifica-se que o membro 4 (baterista) da banda é o elemento que está submetido ao maior nível sonoro durante os ensaios.

Através da análise dos níveis sonoros dos períodos analisados (Tabela 2), é possível determinar a tolerância de tempo permitida para cada faixa de nível sonoro, conforme prevê a NR-15.

Na Tabela 3 estão quantificados os valores referentes à média dos níveis de pressão sonora dos três dias de análise, arredondados convenientemente, confrontados com a máxima exposição diária permissível pela NR-15. Observa-se na referida Tabela que, segundo a NR15, o membro 4 da banda só poderia ficar exposto no máximo durante 17,5 minutos aos 109 $\mathrm{dB}(\mathrm{A})$, sendo que os demais elementos poderiam ficar expostos aos $107 \mathrm{~dB}(\mathrm{~A})$ por no máximo 22,5 min.

Considerando que a duração média do tempo do ensaio e dos shows da banda é de duas (2) horas, é possível estimar a dose de ruído (ver item 2.4) à qual cada componente está submetido. 


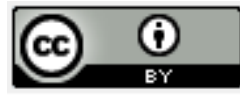

Tabela 3 - Tempo máximo de exposição, segundo a NR-15, para os níveis de pressão sonora obtidos nos 5 integrantes da banda

\begin{tabular}{c|c|c}
\hline Membro & NPS, dB (A) & $\begin{array}{c}\text { Máxima exposição diária } \\
\text { permissível (minutos) }\end{array}$ \\
\hline 1 & 107 & 22,5 \\
\hline 2 & 107 & 22,5 \\
\hline 3 & 107 & 22,5 \\
\hline 4 & 109 & 17,5 \\
\hline 5 & 107 & 22,5 \\
\hline
\end{tabular}

Na Tabela 4 estão apresentadas as doses de ruído calculadas para cada membro da banda. Nota-se que todos os integrantes estão expostos a doses de ruído acima do permitido, mostrando a necessidade dos mesmos se protegerem eficazmente.

Tabela 4 - Dose de ruído submetida aos indivíduos analisados

\begin{tabular}{c|c}
\hline Membro & Dose de Ruído (\%) \\
\hline 1 & 533 \\
\hline 2 & 533 \\
\hline 3 & 533 \\
\hline 4 & 686 \\
\hline 5 & 533 \\
\hline
\end{tabular}

\subsubsection{Recomendações para se amenizar o ruído e/ou seus efeitos nos ensaios}

Como forma de se reduzir o efeito do ruído nos músicos durante seus ensaios, sugerese a utilização de protetores auditivos. A seguir serão analisados dois tipos distintos de protetores auriculares facilmente encontrados no mercado:

- Protetor auditivo do tipo inserção com Nível de Redução de Ruído (NNRsf) de $15 \mathrm{~dB}(\mathrm{~A})$;

- Protetor auditivo do tipo concha com Nível de Redução de Ruído (NNRsf) de $22 \mathrm{~dB}(\mathrm{~A})$;

Através dos valores de atenuação dos dispositivos de proteção sugeridos, é possível, a partir de um método simples de análise, verificou os níveis sonoros resultantes com a utilização de tais equipamentos.

O método consiste na avaliação do índice de Nível de Redução de Ruído (NNRsf), que é usado para o cálculo do nível de pressão sonora protegido. Esse índice é definido baseado nas recomendações de Niosh (1975) apud Gerges (2000) e calculado a partir de ensaio 


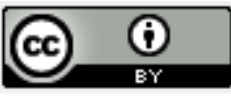

conforme as normas internacionais ANSI S3.19/1974 e S12.6/1984. O nível de pressão sonora proporcionado com o uso do protetor auditivo é calculado através diferença do NPS medido no ambiente e o nível de redução de ruído (NNRsf) do protetor auricular, conforme a Equação 3.

$$
N P S_{c}(d B(A))=N P S_{s}-N N R s f
$$

onde:

"NPS " é o Nível de Pressão Sonora atenuado;

"NPS " é o Nível de Pressão Sonora ambiente, em dB(A);

"NNRsf” é o Nível de Redução de Ruído do equipamento de proteção, em dB(A).

Desta forma, com o uso da Equação 3 pode-se reescrever os valores de NPS a que os indivíduos da banda foram submetidos. Os valores promovidos pela atenuação com os dois tipos de protetores são apresentados na Tabela 5.

Tabela 5 - Valores de NPS promovidos com a atenuação dos protetores auditivos

\begin{tabular}{c|c|c|c|c|c}
\hline \multirow{2}{*}{ Membro } & \multirow{2}{*}{ NPS, dB(A) } & \multicolumn{2}{|c|}{ NNRsf, dB(A) } & \multicolumn{2}{c}{ NPS $_{\mathbf{c}}, \mathbf{d B}(\mathbf{A})$} \\
\cline { 3 - 6 } & $\begin{array}{c}\text { Protetor de } \\
\text { inserção }\end{array}$ & $\begin{array}{c}\text { Protetor } \\
\text { tipo concha }\end{array}$ & $\begin{array}{c}\text { Protetor de } \\
\text { inserção }\end{array}$ & $\begin{array}{c}\text { Protetor } \\
\text { tipo concha }\end{array}$ \\
\hline 1 & 107 & 15 & 22 & $\mathbf{9 2}$ & $\mathbf{8 5}$ \\
\hline 2 & 107 & 15 & 22 & $\mathbf{9 2}$ & $\mathbf{8 5}$ \\
\hline 3 & 107 & 15 & 22 & $\mathbf{9 2}$ & $\mathbf{8 5}$ \\
\hline 4 & 109 & 15 & 22 & $\mathbf{9 4}$ & $\mathbf{8 7}$ \\
\hline 5 & 107 & 15 & 22 & $\mathbf{9 3}$ & $\mathbf{8 6}$ \\
\hline
\end{tabular}

Analogamente, as Tabelas 3 e 4 podem ser reescritas admitindo novos valores limites de exposição, de acordo com a NR-15 e calculando os novos valores de dose de ruído a partir dos valores de NPS promovidos com a atenuação dos níveis sonoros dos dois protetores analisados. Os valores reavaliados estão expressos nas Tabelas 6 e 7. 
Tabela 6 - Valores máximos diários permissíveis promovidos com o uso dos protetores auditivos

\begin{tabular}{c|c|c|c|c}
\hline \multirow{2}{*}{ Membro } & \multicolumn{2}{|c|}{ NPS $_{\mathbf{c}}, \mathbf{d B}(\mathbf{A})$} & \multicolumn{2}{c}{$\begin{array}{c}\text { Máxima exposição diária } \\
\text { permissível (horas) }\end{array}$} \\
\cline { 2 - 5 } & $\begin{array}{c}\text { Protetor de } \\
\text { inserção }\end{array}$ & $\begin{array}{c}\text { Protetor } \\
\text { tipo concha }\end{array}$ & $\begin{array}{c}\text { Protetor de } \\
\text { inserção }\end{array}$ & $\begin{array}{c}\text { Protetor tipo } \\
\text { concha }\end{array}$ \\
\hline 1 & 92 & 85 & $\mathbf{3}$ & $\mathbf{8}$ \\
\hline 2 & 92 & 85 & $\mathbf{3}$ & $\mathbf{8}$ \\
\hline 3 & 92 & 85 & $\mathbf{3}$ & $\mathbf{8}$ \\
\hline 4 & 94 & 87 & $\mathbf{2 , 2 5}$ & $\mathbf{6}$ \\
\hline 5 & 93 & 86 & $\mathbf{2 , 5}$ & $\mathbf{7}$ \\
\hline
\end{tabular}

Tabela 7 - Doses de ruído promovidas com o uso dos protetores auditivos

\begin{tabular}{c|c|c}
\hline \multirow{2}{*}{ Membro } & \multicolumn{2}{|c}{ Dose de Ruído (\%) } \\
\cline { 2 - 3 } & $\begin{array}{c}\text { Protetor de } \\
\text { inserção }\end{array}$ & $\begin{array}{c}\text { Protetor } \\
\text { tipo concha }\end{array}$ \\
\hline 1 & 66,7 & $\mathbf{2 5 , 0}$ \\
\hline 2 & $\mathbf{6 6 , 7}$ & $\mathbf{2 5 , 0}$ \\
\hline 3 & $\mathbf{6 6 , 7}$ & $\mathbf{2 5 , 0}$ \\
\hline 4 & $\mathbf{8 8 , 9}$ & $\mathbf{3 3 , 3}$ \\
\hline 5 & $\mathbf{8 0 , 0}$ & $\mathbf{2 8 , 6}$ \\
\hline
\end{tabular}

Da avaliação dos dois equipamentos escolhidos para a análise de proteção individual, nota-se que o protetor auditivo do tipo concha apresenta atenuações maiores que a do tipo inserção, porém, para a análise em questão (shows e/ou ensaios com duração média de duas horas), os dois equipamentos encontram-se sob condições de atender ergonomicamente a situação. Contudo cabe ressaltar que, analisando de uma forma mais estética, o protetor tipo inserção seria mais indicado na atividade relacionada, uma vez que contempla a redução de ruído necessária para a realização da tarefa. 


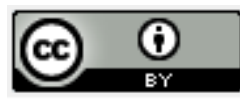

A Tabela 8 relaciona os valores percentuais de redução proporcionada com o uso dos protetores individuais dos valores de NPS e dose de ruído e o aumento do tempo de exposição máxima diária permitida pela NR-15.

Tabela 8 - Valores percentuais de reduções de NPS e dose de ruído, e aumento percentual do tempo máximo de exposição diária conforme NR-15

\begin{tabular}{|c|c|c|c|c|c|c|}
\hline \multirow{3}{*}{ Membro } & \multicolumn{2}{|c|}{ Redução do NPS } & \multicolumn{2}{|c|}{$\begin{array}{l}\text { Redução da dose de } \\
\text { ruído }\end{array}$} & \multicolumn{2}{|c|}{$\begin{array}{l}\text { Aumento do tempo máximo } \\
\text { de exposição diária }\end{array}$} \\
\hline & \multicolumn{6}{|c|}{$(\%)$} \\
\hline & $\begin{array}{l}\text { Protetor } \\
\text { de } \\
\text { inserção }\end{array}$ & $\begin{array}{c}\text { Protetor } \\
\text { tipo } \\
\text { concha }\end{array}$ & $\begin{array}{c}\text { Protetor } \\
\text { de } \\
\text { inserção }\end{array}$ & $\begin{array}{c}\text { Protetor } \\
\text { tipo } \\
\text { concha }\end{array}$ & $\begin{array}{c}\text { Protetor } \\
\text { de } \\
\text { inserção }\end{array}$ & $\begin{array}{c}\text { Protetor } \\
\text { tipo } \\
\text { concha }\end{array}$ \\
\hline 1 & 14,1 & 20,6 & 87,5 & 95,3 & 700 & 2033 \\
\hline 2 & 14,1 & 20,6 & 87,5 & 95,3 & 700 & 2033 \\
\hline 3 & 14,1 & 20,6 & 87,5 & 95,3 & 700 & 2033 \\
\hline 4 & 13,8 & 20,2 & 87,0 & 95,1 & 671 & 1957 \\
\hline 5 & 13,9 & 20,4 & 86,7 & 95,2 & 650 & 2000 \\
\hline
\end{tabular}

\subsection{RESULTADOS DAS MEDIÇÕES NA CASA DE SHOWS}

Conforme já mencionado, o integrante mais crítico foi o baterista (membro 4). $\mathrm{Na}$ Tabela 9, pode-se visualizar o maior valor de NPS encontrado, bem como o intervalo de NPS e os valores médios obtidos após as medições feitas no ouvido do baterista na casa de shows.

Tabela 9 - Valores obtidos a partir do acompanhamento do membro 4 da banda

\begin{tabular}{c|c|c}
\hline $\mathbf{N P S}_{\text {máx }} \mathbf{d B}(\mathbf{A})$ & Intervalo de NPS observado dB(A) & Valor médio dB(A) \\
\hline 121,2 & 103,0 a 110,0 & 107,6 \\
\hline
\end{tabular}

Analisando a Tabela 9, nota-se que os valores de NPS obtidos após o acompanhamento na casa de shows são muito próximos aos obtidos no ambiente de ensaio (variação menor que 1\%). Isto pode ser explicado pelo fato dos equipamentos (fontes sonoras) utilizados em palco na casa de shows e no estúdio serem os mesmos.

As diferenças nos valores de ruído observados para ambos recintos de atividade dos músicos ocorre devido à acústica do ambiente, às diferentes distâncias entre os equipamentos geradores de som e os músicos e à presença de ruídos de fundo. Porém, destaca-se que o ruído 


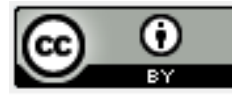

de fundo apresenta pouca influência sobre a banda, devido ao fato de que os níveis de som emitidos pela banda serem maiores que o ruído de fundo. Assim, o principal problema para os músicos é o som gerado por eles próprios.

\subsubsection{Recomendações para se amenizar o ruído e/ou seus efeitos em shows}

As medidas preventivas de proteção individual sugeridas e possíveis de serem adotadas para o caso de atividade na casa de shows podem ser as mesmas referenciadas e comentadas para o caso do ambiente de ensaio, pelo fato dos valores médios de NPS serem praticamente iguais.

Observa-se também para o caso de shows, uma maior tendência em se optar pelo protetor auditivo de inserção ao invés do tipo de concha, devido ao fator estético.

\section{CONCLUSÕES}

Conclui-se que os valores de Níveis de Pressão Sonora observados nos músicos foram extremamente elevados, estando todos acima dos limites recomendados pelas normas, e merecem uma análise para prevenir os riscos de saúde ocupacional. A adoção de medidas consideradas simples pode refletir em melhorias substanciais na redução do nível de exposição ao ruído.

A comparação dos ambientes avaliados (estúdio de ensaio e casa de shows), mostrou que os níveis de exposição foram praticamente iguais para ambos os casos analisados. Admite-se, entretanto, que podem ocorrer diferenças maiores para esses níveis de ruído para outras casas de shows, em virtude de diferentes tipos de sonorização e acústica do ambiente. Destaca-se que entre os 5 integrantes da banda que foram analisados (tanto nos ensaios como no show), o membro que ficou na maioria das vezes submetido aos maiores níveis de pressão sonora foi o baterista, o que pode ser explicado principalmente pelos tipos de músicas executadas pela banda, que exigem muito especificamente deste elemento.

Também é importante ressaltar que é necessário atentar-se, na fase de projeto, para as concepções acústico-arquitetônicas de um ambiente, pois ações corretivas tomadas depois do ambiente já estar construído tornam-se muito mais onerosas e, muitas vezes, não viáveis economicamente. 


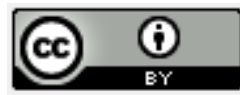

Por fim, sugere-se a utilização de protetores auriculares para os músicos se protegerem do elevado nível de pressão sonora ao qual estão expostos. Porém, cabe ressaltar que tal proteção, pode, embora não tenha sido ainda cientificamente provado, reduzir a intensidade sonora do retorno dos músicos. Contudo é melhor se ter certa dificuldade com o retorno do que correr o risco de sofrer perdas auditivas irreversíveis. Desta forma, acredita-se que a utilização de protetores auriculares (que devem possuir o Certificado de Aprovação do Ministério do Trabalho e Emprego) para estes profissionais é imprescindível, mesmo que a maioria ainda relute e questione tal importância.

\section{REFERÊNCIAS}

Associação Brasileira de Normas Técnicas. NBR 10.151: Acústica - Avaliação do ruído em áreas habitadas, visando o conforto da comunidade. Rio de Janeiro, 2000.

Associação Brasileira de Normas Técnicas. NBR 10.152: Níveis de ruído para conforto acústico. Rio de Janeiro, 1987.

ALMEIDA, S. I. C. de et al. História natural da perda auditiva ocupacional provocada por ruído. Revista Brasileira de Otorrinolaringologia. Vol. 46, n. 2. São Paulo: 2000.

ASSOCIAÇÃO DOS MORADORES DO DISTRITO DE ÈVORA (AMDE). Évora Portugal, 2003. Disponível em: <http://www.amde.pt>. Acesso em: 09 jul. 2006.

ANDRADE, A. I. A.; LIMA, M. L. L. T.; OLIVEIRA, L. C. S.; RUSSO, I. C. P. Avaliação auditiva em músicos de frevo e maracatu. Revista Brasileira de Otorrinolaringologia. Vol. 68, n. 5. São Paulo: 2002.

BARATA, G.. Doenças ocupacionais afetam saúde dos músicos. Ciência de Cultura, jun./set. 2002, vol.54, no.1, p.13-13. ISSN 0009-6725.

BISTAFA, S. R. B. Acústica Aplicada ao Controle do Ruído. São Paulo: Edgard Blücher, 2006.

BRASIL, Ministério do Trabalho e Emprego. Norma Regulamentadora NR15 - Atividades e Operações Insalubres. Manual de Legislação Atlas. 59a. Edição, 2006a.

BRASIL, Ministério do Trabalho e Emprego. Norma Regulamentadora NR17 - Ergonomia. Manual de Legislação Atlas. 59ª Edição, $2006 b$.

CURRIE, Q.; KENNEDY, J. Musicians and the risk of noise induced hearing loss. The measure online. By Music Industry Association of Newfoundland \& Labrador. Celebrating CBC Issue. Canada, August, 2002. Disponível em: $<$ http://www.mia.nf.ca/themeasure.php?aid=126>. Acesso em: 20 de abr. de 2006. 


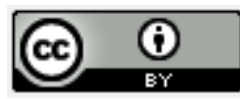

FERNANDES, J. C. Higiene do Trabalho - Acústica e Ruídos. Apostila do Departamento de Engenharia Mecânica da Universidade Estadual Paulista - UNESP - Campus de Bauru, Bauru, São Paulo, 2002.

FERnANDES, J. C. et al. Avaliação do Risco de Perda Auditiva em Músicos. In: XI Simpósio de Engenharia de Produção, Bauru, São Paulo, 2004.

FERNANDES, M.; MORATA, T. C. Estudo dos Efeitos auditivos e extra-auditivos da exposição ocupacional a ruído e vibração. Revista Brasileira de Otorrinolaringologia. Vol. 68, n. 5. São Paulo: 2002.

GERGES, S.N.Y. Ruído: fundamentos e controle. 2a ed. Florianópolis: NR, 2000. 696p.

IIDA, I. Ergonomia - Projeto e Produção. $2^{\circ}$ edição revisada e ampliada. São Paulo: Edgard Blücher, 2005.

PAIXÃO, D. X. da; GRACIOLLI, L. S.; MACIEL, N. I. H. Orientação preventiva sobre os efeitos da exposição a níveis sonoros elevados em músicos. In: $4^{\circ}$ Congresso Iberoamericano de Acústica, Guimarães, Portugal, 2004.

RUIZ, C. de A. et al. Manual de Consenso - O estudo do Ruído. São Paulo, 2000. Disponível em <www.higieneocupacional.com.br/download/ruido-conrado.doc > . Acesso em: 20 de maio de 2006.

TOPPILA, E.; LAITINEN, H.; KUISMA, K. Hearing loss among classical music players. American Industrial Hygiene Conference and Expo. Edited from American Industrial Hygiene Association. Paper 56, 2004. Disponível em: <http://www.aiha.org/abs04/po109.htm>. Acesso em: 20 de abr. de 2006. 